Bio-grafía. Escritos sobre la Biología y su Enseñanza. ISSN 2027-1034

Número Extraordinario. p.p. 326-333

Memorias del Primer encuentro ambiental Universidad, ambiente y sustentabilidad: experiencias y prácticas.

\title{
TALLER DE AVES Y MARIPOSAS: UN REFERENTE PARA LA BIODIVERSIDAD Y LOS CONFLICTOS SOCIOAMBIENTALES.
}

\author{
Cárdenas Yeisson, \\ Dueñas Paola, \\ Lozano Karol, \\ Palacios Alejandra, \\ Rojas Juan Carlos. ${ }^{1}$
}

\section{Resumen}

Aves y Mariposas; es un taller reflexivo que permitió a sus participantes acercarse a la realidad contextual que viven estos dos grupos de seres vivos, los cuales cumplen un papel fundamental en diversos ecosistemas. Por medio de una muestra audiovisual y sensorial se busca que cada participante pueda observar, sentir y percibir las numerosas especies que se pueden encontrar en Colombia y al mismo tiempo generar conciencia acerca de las implicaciones y consecuencias que generan los conflictos socioambientales, que no solo afectan a estos dos diversos grupos, sino que a toda la relación existente entre la vida.

Palabras clave: Aves, Mariposas, Biodiversidad, Conflictos socioambiéntales, Enseñanza de la biología.

\section{Abstract}

Birds and Butterflies is a seminar that allows the participants to approach the contextual reality that these two groups of living beings, which meet an important subject in various ecosystems. Through an audiovisual and sensorial experience, it is sought that each participant can see, feel and perceive the numerous species that can be found in Colombia and at the same time generate awareness about the implications and consequences about the socioenvironmental conflicts that not only affect these two different groups but also the whole relationship between life.

1 Universidad Pedagógica Nacional. - Profesores en formación inicial - Departamento de Licenciatura en Biología - dbi_yrcardenas964@pedagogica.edu.co 
Bio-grafía. Escritos sobre la Biología y su Enseñanza. ISSN 2027-1034

Número Extraordinario. p.p. 326-333

\begin{abstract}
Memorias del Primer encuentro ambiental Universidad, ambiente y sustentabilidad: experiencias y prácticas.
\end{abstract}

Key Words: Birds, Butterflies, Biodiversity, Socio-environmental conflicts, teaching of biology.

\title{
INTRODUCCIÓN
}

De este primer encuentro surge la idea de proponer un taller que permita a los participantes acercarse a la realidad contextual que viven estos dos grupos de seres vivos; aves y mariposas, animales que cumplen un papel fundamental en diversos ecosistemas, por medio una muestra audiovisual y sensorial se buscó que cada sujeto pudiera observar, sentir y percibir las numerosas especies que se pueden encontrar en Colombia, pero también las implicaciones y consecuencias que generan los conflictos socioambientales y que no afectan solo a estos dos diversos grupos sino a toda la relación existente entre la vida.

\section{OBJETIVOS}

Simular un ambiente de museo interactivo donde se expongan imágenes y colecciones de diferentes aves y mariposas de Colombia, acompañadas de sonidos y herramientas audiovisuales.

\section{ESPECÍFICOS}

- Resaltar la importancia de las aves y mariposas en un país megabiodiverso como Colombia.

- Comprender las problemáticas socio-ambientales que afectan la vida y existencia de estos grupos representativos en nuestro territorio.

- Suscitar la reflexión en cada uno de los participantes por medio de las diferentes muestras senso-auditivas.

\section{DURACIÓN: 45 MINUTOS}

\section{ACTIVIDADES}

¿De dónde surge el interés por proponer esta propuesta? 


\section{Bio-grafía. Escritos sobre la Biología y su Enseñanza. ISSN 2027-1034 \\ Número Extraordinario. p.p. 326-333

\begin{abstract}
Memorias del Primer encuentro ambiental Universidad, ambiente y sustentabilidad: experiencias y prácticas.
\end{abstract}

Es clave reconocer que cuando se habla de diversidad no se puede reducir netamente a lo biológico, existe una diversidad humana que nos hace ser, vivir, sentir y pensar diferente, a esto se le reconoce como la diversidad cultural, por esta misma razón surge en el grupo de autores esta propuesta, contemplando los intereses de todos, entonces, tenemos al "colibri" aficionado por las aves y la fotografía, a las mujeres mariposas lindas y encantadoras por este misterioso organismo, y a los que andan problematizando la vida, como muy bien dicen por ahí buscándole la comba al palo, en este sentido, se pretende hacer visible el impacto humano sobre los ecosistemas de estos dos grupos de organismos y socializarlo con niños, niñas, jóvenes, adultos, mayores, siendo esta la estrategia para entre todos tejer "la mochila de los sueños", mochila en la cual se guardan y se transforman las esperanzas, las utopías, se construyen identidades, conocimientos y se proponen alternativas en pro de defender los derechos por la vida.

Así surge el interés de generar un escenario diverso con varias propuestas audiovisuales donde se pueda observar, sentir, escuchar y dialogar, propiciando un espacio para que los sentidos se agudicen y se perciba de múltiples maneras la belleza e importancia de estos dos grupos de organismos, además de incluir los conflictos socio-ambientales que los afectan directamente; para esto se retomaron algunos videos realizados por Yeisson Ricardo Cárdenas y el Grupo de Ornitología de la Universidad Pedagógica Nacional (UPN-O) en las distintas salidas de campo y viajes por diversos lugares de Colombia, evidenciando una pequeña parte de la avifauna que se encuentra en nuestro país y reflejando la diversidad de colores, formas y cantos de estos increíbles animales construyendo así un video donde se refleja las diferentes interacciones ecológicas que tienen las aves en los ecosistemas ${ }^{2}$.

En cuanto a las mariposas, se registró el ciclo de vida de Dione moneta poeyi con la intencionalidad de evidenciar y conocer las diferentes etapas, (huevo, larva, pupa y adulto "mariposa") para esto de utilizo un estereoscopio. De igual manera se mostró una colección didáctica de diversas mariposas la cual permitió la explicación de sus características

\footnotetext{
${ }^{2}$ Videos disponibles en https://goo.gl/r5KcXj
} 


\section{Bio-grafía. Escritos sobre la Biología y su Enseñanza. ISSN 2027-1034 \\ Número Extraordinario. p.p. 326-333

\begin{abstract}
Memorias del Primer encuentro ambiental Universidad, ambiente y sustentabilidad: experiencias y prácticas.
\end{abstract}

propias y únicas reflejando el sorprendente y hermoso mundo de las mariposas de Colombia.

Por otro lado, se realizó una galería fotográfica, la cual fue producto de la salida de campo a la Amazonia Colombiana en el 2015-II, este material que fue registrado por los compañeros y los autores de este documento, brinda la posibilidad de compartir esta experiencia con los asistentes al taller, de manera que se refleja la importancia de la fotografía en las salidas de campo puesto que esta, no solo es una herramienta visual, desde esta se revive la memoria, se reconoce, se re-encuentra y se sorprende lo relacionado con diversas temáticas, en este caso, la biodiversidad de mariposas y aves en Colombia.

Con este taller se proponen otras formas de aprender a través de las muestras audiovisuales presentes en la enseñanza de la Biología, debido a que la imagen permite generar múltiples sensaciones y es un medio de comunicación útil; en este sentido como lo afirma Sánchez (2009) "La fotografía es un medio de comunicación que permite desde la imagen mayores posibilidades de enseñanza y aprendizaje. Es un recurso necesario y fundamental para el desarrollo de actividades en las aulas, tanto en el ámbito de la investigación como en los niveles lúdicos y creativos"

Todas estas muestras están relacionadas con un mural que se realizó donde se colocaron imágenes, palabras y noticias de las problemáticas socioambientales que atraviesa el país, como lo son: la minería, la pérdida de ecosistemas, el hábitat de muchas especies, la contaminación, el tráfico ilegal de especies entre otras, las cuales a su vez que afectan a toda la trama de la vida. También se dieron a conocer datos estadísticos de la biodiversidad que alberga Colombia en cuanto a flora, fauna, microorganismos y ecosistemas, mostrando por qué es un país tan diverso, así mismo evidenciando una tasa de extinción alta, la cual está relacionada con las problemáticas socio-ambientales. Con ello se pretendía que los participantes se informarán y salieran con la chispa de la duda o quizá la reflexión en un nivel más profundo. Para finalizar se realizó una actividad con greda donde cada participante debía construir una imagen relacionada con lo abordado en el taller, además de fomentar la creatividad, la imaginación y activar los sentidos. 
Bio-grafía. Escritos sobre la Biología y su Enseñanza. ISSN 2027-1034

Número Extraordinario. p.p. 326-333

Memorias del Primer encuentro ambiental Universidad, ambiente y sustentabilidad: experiencias y prácticas.

\section{REFLEXIONES}

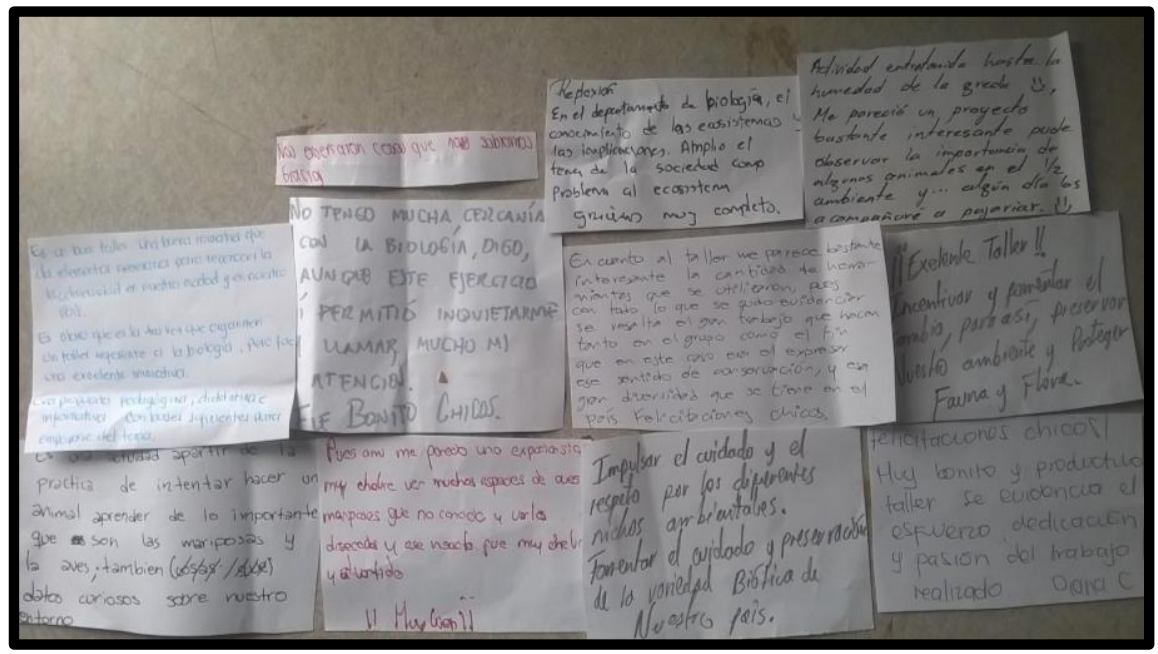

Imagen 1. Algunas reflexiones escritas de los participantes. Tomado por Gallego, S. (2016)

De este primer encuentro ambiental se puede resaltar la importancia que tienen estos eventos académicos en la Universidad, pues de esta manera es posible problematizar los diferentes conflictos socio-ambientales que en este momento atraviesa Colombia y poder socializarlas con varias personas entre ellos estudiantes de secundaria de diferentes instituciones educativas, siendo esta una oportunidad enriquecedora.

Con el taller propuesto "Aves y Mariposas: un referente para la biodiversidad y los conflictos socio-ambientales" se puede concluir que tuvo un impacto positivo para los asistentes, varios de estos no estudiaban carreras afines a la biología, los cuales aseguraban no tener ningún acercamiento con esta ciencia, ni conocimiento de la importancia que tienen las aves y las mariposas dentro de la biodiversidad colombiana. Se resalta la reflexión de uno de los participantes cuando afirmó: "no tengo mucha cercanía con la biología, digo, aunque este ejercicio permitió inquietarme y llamar mucho mi atención". Además, varios, desconocían los problemas sociombientales que afectan estas poblaciones de organismos, algunos de ellos se comprometieron a difundir lo aprendido en el taller en pro de conservar y respetar la vida de estas especies. 
Bio-grafía. Escritos sobre la Biología y su Enseñanza. ISSN 2027-1034

Número Extraordinario. p.p. 326-333

\begin{abstract}
Memorias del Primer encuentro ambiental Universidad, ambiente y sustentabilidad: experiencias y prácticas.
\end{abstract}

Por otra parte, es importante fomentar este tipo de actividades no solo a nivel universitario, sino también en los diferentes escenarios educativos para que así se genere una relación y un impacto. Finalmente, como futuros Licenciados en Biología, esta experiencia nos deja como aprendizaje, que el aula de clase es unos de los muchos lugares para suscitar la reflexión, para discutir y plantear diferentes actividades que generen sensaciones en tanto estudiantes como maestros.

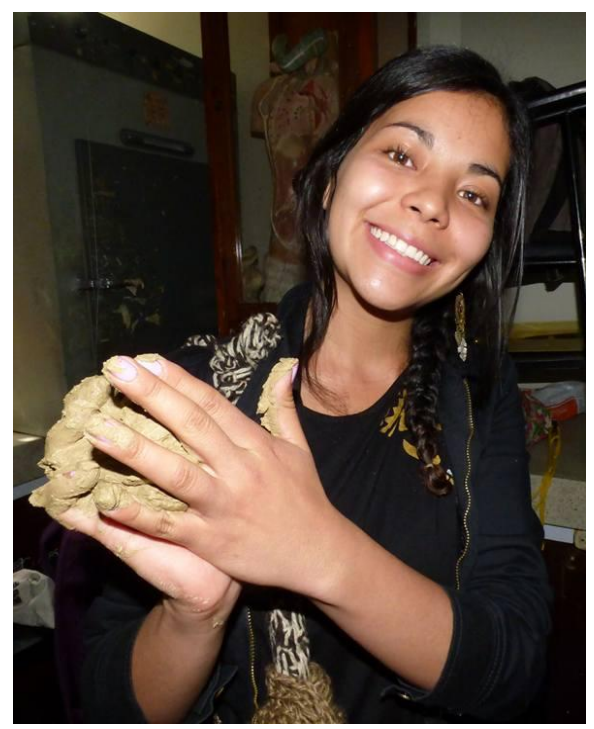

Imagen 2. Recreando la vida con sus manos. Tomada por: Cárdenas Y. \& Gallego, S. (2016)

Finalizando el taller con la actividad de greda. 
Bio-grafía. Escritos sobre la Biología y su Enseñanza. ISSN 2027-1034

Número Extraordinario. p.p. 326-333

Memorias del Primer encuentro ambiental Universidad, ambiente y sustentabilidad: experiencias y prácticas.

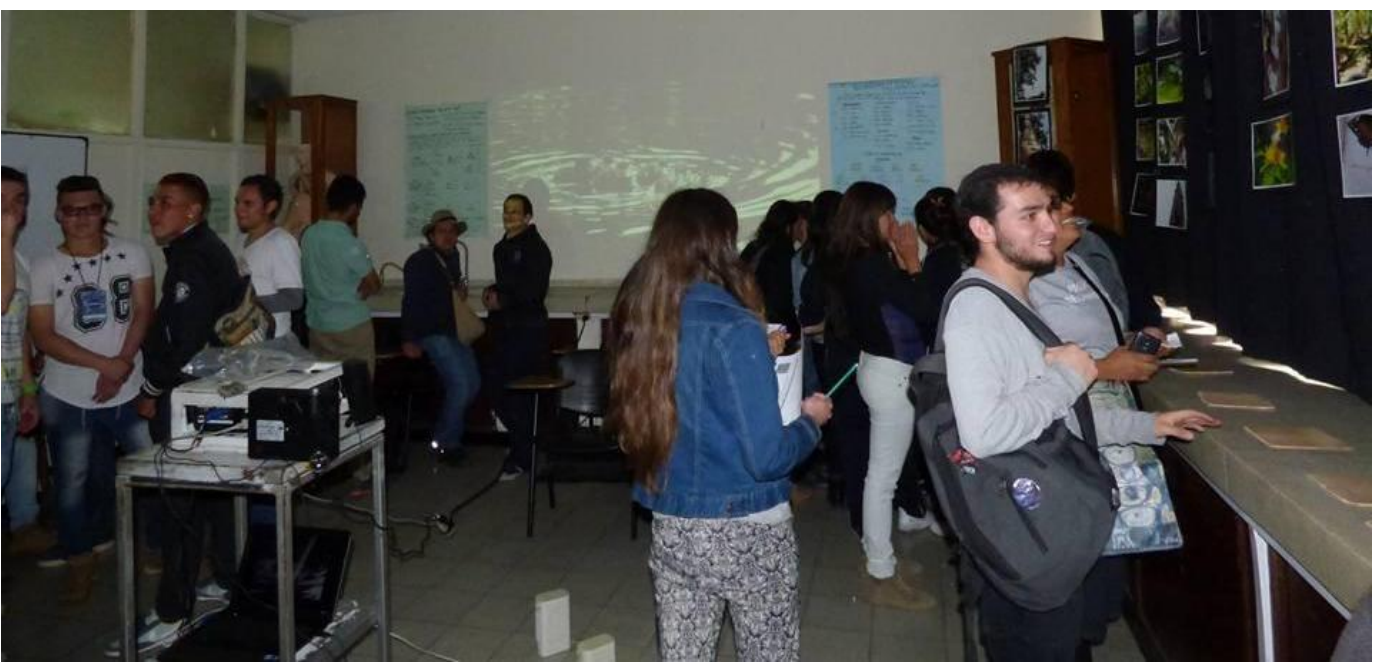

Imagen 3: Explorando y sintiendo. Tomada por Gallego, S. (2016)

Observando las diferentes interacciones de las aves por medio del video.

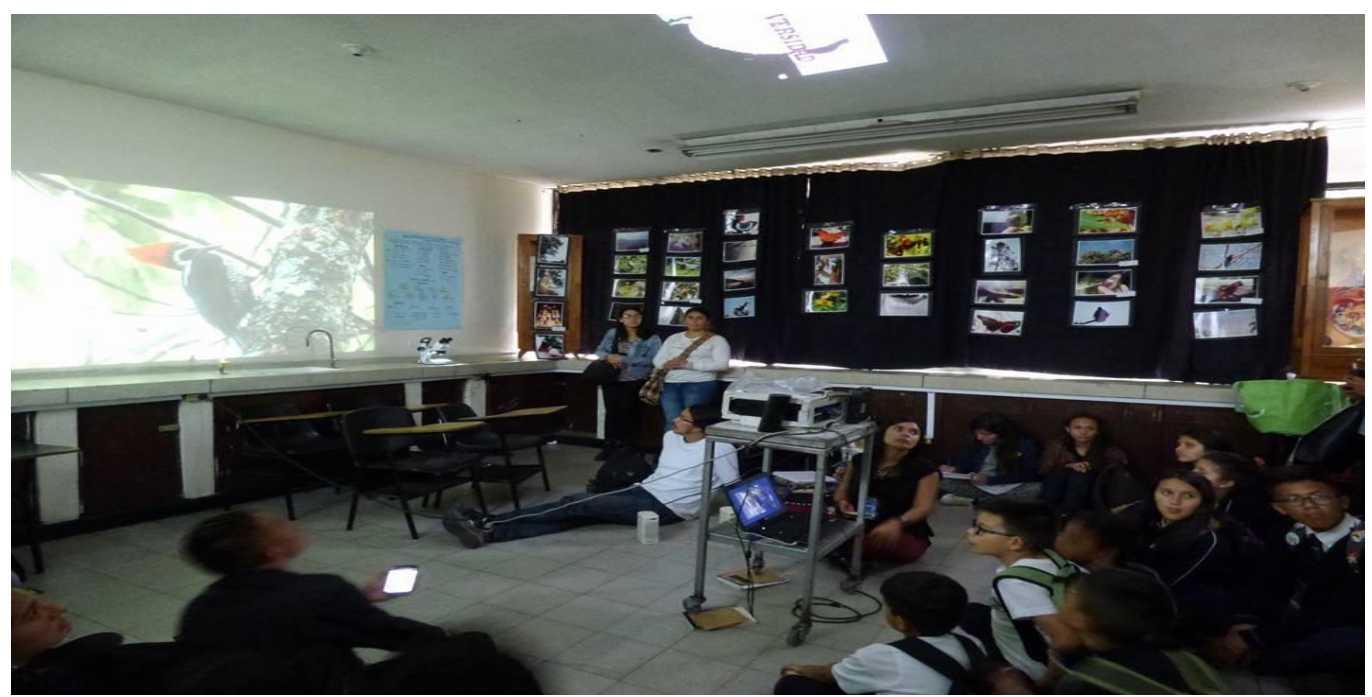

Imagen 4: Interactuando. Tomada por Gallego, S. (2016)

Los participantes analizando las problemáticas socio-ambientales de Colombia. 
Bio-grafía. Escritos sobre la Biología y su Enseñanza. ISSN 2027-1034

Número Extraordinario. p.p. 326-333

Memorias del Primer encuentro ambiental Universidad, ambiente y sustentabilidad: experiencias y prácticas.

\section{REFERENCIAS BIBLIOGRÁFICAS}

ABO. (2000). Aves de la Sabana de Bogotá: Guía de campo. (2a reimpresión). Asociación Bogotana de Ornitología y Corporación Autónoma Regional. Bogotá D. C., Colombia.

Cárdenas, Y. (2016) Colombia el país de las aves, Bogotá. Colombia.

Cortes, C. \& Fagua, G. (2003). Diversidad de arañas de estrato rasante en transeptos borde interior de un bosque del piedemonte cordillerano (Medina, Cundinamarca). Rev. Col. Ent., 29 (2): 113-120

Catálogo de la Biodiversidad de Colombia. recuperado de http://catalogo.biodiversidad.co/?q=lepidoptera\&pagesize=20\&sort=betterMat $\underline{\text { ch\&order=asc\&page }=1}$

Gallego, S (2016). Registro fotográfico del Encuentro Ambiental. Universidad Pedagógica Nacional. Bogotá. Colombia.

Montero, F., \& Ortiz, M. (2013). Aporte al conocimiento para la conservación de las mariposas (Hesperoidea y Papilionoidea) en el páramo el Tablazo Cundinamarca (Colombia). Boletín Científico. Museo de Historia Natural.

Renjifo, L. M., A. M. Franco-Maya, J. D. Amaya-Espinel, G. Cattan y B. López-Lanús (Eds.). (2002). Libro Rojo de las Aves de Colombia. Serie Libros Rojos de Especies Amenazadas de Colombia. Instituto de Investigación de Recursos Biológicos Alexander von Humboldt y Ministerio de Medio Ambiente. Bogotá, Colombia.

Tráfico ilegal de especies en Colombia. (2015). Recuperado en:http://www.proaves.org/trafico-ilegal-de-especies-en-colombia/ 